\title{
Effects of Tributyltin (TBT) on Rat Bone and Mineral Metabolism
}

\author{
Ludmilla Carvalho Rangel Resgala ${ }^{a, b, c}$ Higor Scardini Santana ${ }^{a, d}$ \\ Bruna Souza Mendonça Portela ${ }^{a, c, e} \quad$ Maria Victória Souza Zanovello ${ }^{a}$ \\ Charles Santos da Costa ${ }^{f, g}$ Oscar Mauricio Santamaria Niñof,g \\ Nicolle Endlich Bicudo ${ }^{a}$ Diandra Zipinotti dos Santos ${ }^{\text {h }}$ Priscila Lang Podratz ${ }^{\mathrm{f}, \mathrm{g}}$ \\ Maura da Cunhai Andre Lacerda de Abreu Oliveira ${ }^{i}$ \\ Leandro Ceotto Freitas Lima ${ }^{f, g} \quad$ Neuza Felix Gomes-Rochette ${ }^{a}$
}

Leticia Batista Azevedo Rangel ${ }^{b, d, h} \quad$ Jones Bernardes Graceli ${ }^{f, g} \quad$ lan Victor Silva ${ }^{a, b, d}$

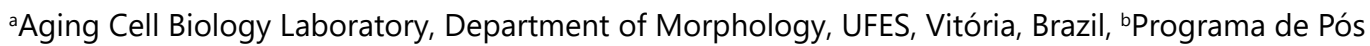
Graduação em Biotecnologia (UFES/RENORBIO), Health Sciences Center, UFES, Vitória, Brazil, 'Centro Universitário Redentor (UniREDENTOR), Itaperuna, Brazil, dPrograma de Pós Graduação em Bioquímica e Farmacologia, Department of Physiological Sciences, Health Sciences Center, UFES, Vitória, Brazil, eHospital Universitário Antônio Cassiano de Moraes (HUCAM), Health Sciences Center, UFES, Vitória, Brazil, fPrograma de Pós Graduação em Ciências Fisiológicas, Department of Physiological Sciences, Health Sciences Center, UFES, Vitória, Brazil, gLaboratory of Endocrinology and Cellular Toxicology, Department of Morphology, Health Sciences Center, UFES, Vitória, Brazil, hLaboratory of Cellular and Molecular Biology of Human Cancer, Department of Pharmaceutical Sciences, Health Sciences Center, UFES, Vitória, Brazil, 'Laboratory of Cell Biology, Biotechnology Center, UENF, Campos dos Goytacazes, Vitória, Brazil,

\section{Key Words}

TBT • Bone • Estrogen • Ultrastructural changes $•$ Mineral metabolism

\begin{abstract}
Background/Aims: Tributyltin (TBT) is an organotin (OTs) and biohazard organometallic pollutant. Recently our group has shown that TBT, even in very low doses, has deleterious effects on several tissues most likely due to its role as an endocrine-disrupting molecule. Other studies have confirmed that OT exposure could be responsible for neural, endocrine, and reproductive dysfunctions via in vitro and in vivo models. However, TBT effects on bone lack concise data despite the fact that bone turnover is regulated by endocrine molecules, such as parathormone (PTH), estrogen (E2), etc. Our group has already shown that TBT disrupts adrenal and female gonadal functions. Methods: We studied the effects of TBT on bone metabolism and structure using DXA, microCT scan, and SEM. We also determined the calcium $\left(\mathrm{Ca}^{2+}\right)$ and phosphate $(\mathrm{Pi})$ metabolism in TBT-treated rats as well as some biomarkers
\end{abstract}

L. Carvalho Rangel Resgala and H. Scardini Santana contributed equally to this work.

Ian Victor Silva

and Jones Bernardes Graceli
Aging Cell Biology Laboratory, Department of Morphology, UFES,

1468. Marechal Campos Av. Basic I, room 5, 29043-090 Vitoria, ES (Brazil)

Tel.+55-27-99970-1237, E-Mail Ibce18@yahoo.com; jbgraceli@gmail.com 


\section{Cellular Physiology Cell Physiol Biochem 2019;52:1166-1177 \\ \begin{tabular}{ll|l} 
and Biochemistry & $\begin{array}{l}\text { DOl: 10.33594/000000079 } \\
\text { Published online: } 17 \text { April 2019 }\end{array}$ & $\begin{array}{l}\text { O } 2019 \text { The Author(s). Published by } \\
\text { Cell Physiol Biochem Press GmbH\&Co. KG }\end{array}$ \\
\cline { 2 - 3 } &
\end{tabular} \\ Rangel Resgala et al.: TBT on Rat Bone and Mineral Metabolism}

for bone formation and resorption. Results: Surprisingly, we found that TBT leads to higher bone mineral density (BMD) although lesions in spinal bone were observed by either microCT scan or SEM. Biomarkers for bone resorption, such as the urinary deoxipyridinolines (DPD) excretion ratio was increased in TBT-treated animals versus mock-treated controls. Osteocalcin (OC) and alkaline phosphatase (AP) are markers of bone formation and are also elevated suggesting that the bone matrix suffers from a higher turnover. Serum $\mathrm{Ca}^{2+}$ (total and ionized) do not changed by TBT treatment although hypercalciuria is observed. Conclusion: It is known that $\mathrm{Sn}$ atoms have three valence states $\left(\mathrm{Sn}^{2+}, \mathrm{Sn}^{3+}\right.$, and $\left.\mathrm{Sn}^{4+}\right)$; hence, we hypothesized that $\mathrm{Sn}$ (more likely $\mathrm{Sn}^{2+}$ ) could be competing with $\mathrm{Ca}^{2+}$ and/or $\mathrm{Mg}^{2+}$ in hydroxyapatite mineral matrix to disturb bone turnover. Further work is needed to confirm this hypothesis.

(C) 2019 The Author(s). Published by Cell Physiol Biochem Press GmbH\&Co. KG

\section{Introduction}

Organotin (OTs) are organometallic pollutants used in a variety of domestic, industrial, and agricultural products. They are powerful biocidal compound that work against fungi and bacteria $[1,2]$. Tributyltin (TBT) is a class of OTs that contains the $\left(\mathrm{C}_{4} \mathrm{H}_{9}\right)_{3} \mathrm{Sn}$ group and are used for wood preservation, antifouling paints for boats and ships, disinfection of circulating industrial cooling water, and slime control in paper mills [3]. OTs are largely reported as powerful endocrine disruptor compounds (EDCs). There is some scientific evidence that TBT can masculinize the sex organs of the female in several species of meso- and neogastropods resulting in a development of a penis and a vas deferens along with the female sex organs in these mollusks $[1,2,3]$. OTs can also modulate the endocrine system of higher evolved eukaryotes such as mammals.

Our group recently demonstrated that TBT can profoundly affect several fundamental physiological mechanisms through its action on many endocrine glands and hormones [4-15]. Merlo et al. [7] showed that TBT disrupts the hypothalamic-pituitary-adrenal axis leading to dramatic changes into cortisol secretion and regulation of adrenal and hypophysis morphophysiology. The potential inflammatory effect of TBT also leads to renal insufficiency [8]. The toxic mechanism underlying TBT action, in fact, seems to reside in the enhancement of macrophage activation and systemic production of reactive oxygen species (ROS) as observed in the vascular system as well $[9,10,14]$. The toxic effects of TBT are also observed as a decrease in fertility due to deleterious effects in the female hypothalamic-pituitaryovarian axis as well $[4,5,6,14,16]$.

Many of the TBT deleterious effects seem to involve the estrogen receptor alpha (ER $\alpha$ protein $[7,8,14,16,17]$. It is well known that ER $\alpha$ is expressed in bone-forming cells (osteoblast) where it enhances the collagen, sialo-glycoproteins, and y-carboxylated proteins of the bone organic matrix while increasing bone formation and mineralization $[18,19]$. In fact, women and female murine models lack estrogen production (E2) after menopause or castration (ovariectomy- OVX). This lack of E2 leads to low bone mineral density due to cessation of osteoblast ER $\alpha$ stimulation [20,21]. However, little is known about the effects of TBT in bone.

Baker and co-workers [17] showed that TBT impaired the transition from rat bone primary culture of mesenchymal cells into osteoblasts via induction media leading them to differentiate to adipocytes. This is due to inactivation of Parpy and inhibition of genes involved in osteoblast differentiation such as RUNX [22]. Primary bone marrow macrophage cultures showed that TBT marginally inhibited the number of differentiated osteoclasts [23] Our data indicated that TBT disrupts the hormonal system and induces adipogenesis in several tissues; thus, we hypothesized that TBT could also affect bone metabolism in vivo [24].

To investigate this, we treated male rats with our standard protocol [7-10] to evaluate bone metabolism. We found that TBT treatment $(100 \mathrm{ng} / \mathrm{day} / \mathrm{kg}$ of animal) orally administered for 15 consecutive days (control rats received vehicle) show higher bone mineral density (BMD, measured in $\left.\mathrm{g} / \mathrm{cm}^{2}\right)$. However, microanalysis of calcium $\left(\mathrm{Ca}^{2+}\right)$ and phosphate (Pi) 


\section{Cellular Physiology Cell Physiol Biochem 2019;52:1166-1177 \\ \begin{tabular}{c|c|c|c|c|}
\hline DOl: 10.33594/000000079 & O 2019 The Author(s). Published by \\
\hline and Biochemistry &
\end{tabular} \\ Published online: 17 April 2019 Cell Physiol Biochem Press GmbH\&Co. KG \\ Rangel Resgala et al.: TBT on Rat Bone and Mineral Metabolism}

content in bone revealed fewer ions. However, when the DXA data were normalized by bone $\mathrm{Ca}^{2+}+\mathrm{Pi}$ dried mass, as well as analyzed by $\mathrm{T}$ scores, the measurements revealed lower densities in TBT-treated animals. We also performed several experiments including microCT scan, scanning electron microscopy (SEM), and tin (Sn) determination of bones. The MicroCTScan from vertebral bones showed several lesions and lower density. The DXA and microCT scan exhibited distinct results because this work analyzed the tridimensional form and the texture of the bone.

Biomarkers for bone formation such as osteocalcin and alkaline phosphatase (AP) had no change in TBT-treated animals. The urinary deoxipyridinolinic excretion fraction (DPD/creatinine), a marker of bone resorption, increased in TBT-treated rats indicating greater bone loss. Indeed, both urinary $\mathrm{Ca}^{2+}$ and Pi urinary excretion was higher in TBTtreated animals versus controls. In summary, microCT scan and higher urinary $\mathrm{Ca}^{2+}$ and $\mathrm{Mg}^{2+}$ excretion in the TBT-treated animals versus control suggest that the DPD/creatinine urinary excretion in TBT-treated rats corroborated with lower bone density. Indeed, Coutinho et al. [8] showed that renal failure in TBT-treated animals were due to glomerular sclerosis that partially explained the higher amount of $\mathrm{Sn}$ in the urine of these animals. Another possibility is that $27(\mathrm{OH})$ cholesterol would function as a potential agonist of $E R \alpha$ to downregulate the kidneys of TBT-treated animals [25]. At the age of these female rats, E2 is still needed for diametral growth for bones; hence glomerular-tubular sclerosis may be the mechanism even if PTH is normal. Future work will confirm this hypothesis.

Our group has previously shown that E2 status is important for expression of bone biomarkers such as osteocalcin, AP, DPD, and C-terminus tellopeptides of collagen in murine and humans (the $\mathrm{Sn}$ content in bone was 2-fold higher as expected in TBT-treated rats versus control). In summary, we hypothesized that Sn could be exchanged in bone by other divalent cations to enhance bone resorption in TBT-treated animals. This is another endocrinerelated deleterious effect of OTs in mammalian organisms.

\section{Materials and Methods}

\section{Animals and Treatments}

Adult female Wistar rats (12-week-old) were maintained between 23 and $25^{\circ} \mathrm{C}$ with a $12: 12 \mathrm{~h}$ light/ dark cycle. Rat chow and filtered tap water were provided at libitum. The Ethics Committee of Animals Use approved all protocols for Research Welfare of Health Sciences Center from Federal University of Espírito Santo (UFES, $N^{\circ}$ 05/2016). All experiments were performed in accordance with the Biomedical Research Guidelines for the Care and Use of Laboratory Animals available online and followed the recommendations of the American Veterinary Medical Association Guidelines (2007). The rats were split into two groups. Control (mock-treated, $n=5)$ rats were treated daily with the vehicle $(0.4 \%$ ethanol) of TBT. TBT-treated (TBT, $\mathrm{n}=5$ ) rats were given $100 \mathrm{ng} / \mathrm{kg} /$ day TBT, respectively, by gavage for 15 days in a row. Prior to sacrifice ( $24 \mathrm{~h}$ before) all animals were placed individually in metabolic cages for collection of feces and urine as well as measurements of daily food and water intake. All animals were anesthetized using sodium thiopental ( $50 \mathrm{mg} / \mathrm{kg}$, intraperitoneal, Fontoveter, Brazil) before euthanasia, and wet bones were weighed. The bones were then dried to constant weight and ashed in a special oven to measure calcium, phosphorus, magnesium, and tin $[4,15,16]$.

Doses and routes of exposure were chosen based on protocols from our prior studies $[6,10,11]$ and others $[16,18]$; these protocols induce an increase in serum tin levels $[10,11]$. The whole body composition of rodents could be changed with TBT exposure $[14,16,17]$. Hence, the weights of control and TBT groups were assessed at the beginning and end of the study. Tin in the plasma, urine, and bone were measured as described elsewhere $[4,10]$. 


\section{Cellular Physiology Cell Physiol Biochem 2019;52:1166-1177 \begin{tabular}{c|c|c|c|c|}
\hline DOl: 10.33594/000000079 & 02019 The Author(s). Published by \\
\hline
\end{tabular} and Biochemistry Published online: 17 April 2019 Cell Physiol Biochem Press GmbH\&Co. KG \\ Rangel Resgala et al.: TBT on Rat Bone and Mineral Metabolism}

\section{Determination of bone mineral density (BMD) in rats treated with TBT}

Examination of bone mineral density used dual-emission x-ray absorptiometry (DXA) with stateof-the-art equipment (Faxitron 6000c, Switzerland). Data were expressed in $\mathrm{g} / \mathrm{cm}^{2}$ and categorized as osteopenic/osteoporotic $(<-2.0)$ or normal $(-1.0<\mathrm{t}$ score $>-1.5)$. All animals with a $\mathrm{t}$-score range in between -1.5 and -2.0 were selected to minimize the chances of false negatives ( $n=$ one excluded from control group). Furthermore, integrated one-dimensional X-ray cuts $\left(\mathrm{g} / \mathrm{cm}^{2}\right)$ were then normalized by three-dimensional cuts using a t-score determination (also from Faxitron, Switzerland). Data were also normalized by the animal body weight as shown on X-ray. For more details, see Souza et al. [26].

\section{Determination of spinal lumbar lesions in the bones of rats treated with TBT}

MicroCT of the spine (lumbar) bones from rats treated with $100 \mathrm{ng} / \mathrm{kg}$ TBT and controls were done at the Universidade Estadual do Norte Fluminense Darcy Ribeiro (UENF), Campos dos Goytacazes-RJ, Brazil. The samples were placed in the scanner in sternal recumbence, and the tomographic images were rebuilt using a GE Health Care multiplying computed tomography (CT) scanner (model 2290468, GE Inc., USA); images were handled using OsiriX software.

\section{Detection of ultrastructural effects of TBT in rat bone}

To analyze whether TBT had any effect on bone ultrastructure, spinal rat bones from both groups were prepared and analyzed with scanning electron microscopy (SEM). Bones were mechanically cleaned from the muscle and other soft tissues and washed with PBS $\left(0.9 \% \mathrm{NaCl}, 10 \mathrm{mM} \mathrm{Na}_{2} \mathrm{HPO}_{4^{\prime}} / \mathrm{NaH}_{2} \mathrm{PO}_{4} ; \mathrm{pH} 7.4\right)$ three times to extract proteins, maintain $\mathrm{pH}$, avoid artifacts, and control osmolality. After washing, the bones were fixed with a mix of $2 \%$ glutaraldehyde (GA) and $2 \%$ paraformaldehyde (PA) in 1, 4 pipeazinadietanosulfonic acid (PIPES, pH 7.4) buffer. Next, the samples were treated with gradient dehydration in ethanol (30\%, 50\%, $70 \%, 90 \%$, and 100\%, 3 times for 20 minutes each) followed by critical point drying (Bal-Tec CPD 030) where ethanol is gradually replaced by liquid $\mathrm{CO}_{2}$ (White-Martins, Brazil).

The critical point occurs when the interface between $\mathrm{CO}_{2}$ liquid/gas does not exist because the amount of liquid molecules becoming gas is exactly equal to the amount of gas molecules becoming liquid. The temperature was so high, and all of the liquid was in gas phase leaving the sample completely dry. The samples were fixed via carbon ribbon on support stubs. This was placed on the microscope sample holder. The material was at the Bal-Tec unit metallized FCD 050 under an Argon atmosphere and covered with platinum (Pt). The samples were analyzed by scanning electron microscope (model JEOL 6610 LV, JEOL, USA) at $25 \mathrm{KV}$ power. Images were recorded using the manufacture's software.

\section{Mineral and bone metabolism markers determinations}

Urine was tested for common mineral and bone metabolism biomarkers; serum alkaline phosphatase (AP) activity was determined in all samples via spectrophotometric analysis of the endpoint reactionthe standard method used in clinical laboratories (Bioclin, Vitoria, Brazil) following the manufacturer's protocol. The concentration of plasma and urinary calcium (total and ionized), phosphorus, and creatinine were determined calorimetrically also by kits provided by Bioclin following the manufacturer's protocol. Analysis of serum osteocalcin (OC), AP, and urinary deoxipyridinolines (DPD) were determined via ELISA test provided by Metra Bioscience (Metra Bioscience, USA - 16) following the manufacturers' protocol. Plasma and urine calcium $\left(\mathrm{Ca}^{2+}\right)$, phosphorus (Pi), magnesium, and creatinine were determined at the Clinical Chemistry Laboratory Hospital Universitário Antônio Cassiano de Moraes (HUCAM) through standard methods (Bioclin, Vitoria, Brazil). Serum, urinary, and assed bone Sn was measured as described before [3].

\section{Statistical analysis}

Power analysis used SSPS program (SSP Inc., USA) and estimated a minimum sample size of the three animals to reach significance due to the high sensitivity of the assays. The statistical test used to determine the correlation between stratified osteoporosis, osteopenia, and normal relationship between the alleles used the Chi-square $\left(\mathrm{X}^{2}\right)$ for trend. ANOVA and post hoc Bonferroni significance was set at 5\%. Statistical testing and graphing used Graph Pad Prism for Windows (version 5.00.288). 


\section{Results}

Our results by DXA measurements showed that treated female adult rats exhibited a $20 \%$ increase in BMD relative to their MOCK treated groups $\left(180 \mathrm{mg} / \mathrm{cm}^{2}\right.$ for TBT-treated $v s$. $142 \mathrm{mg} / \mathrm{cm}^{2}$ for MOCK treated rats, $\mathrm{p}=0.047$, Fig. 1). However, the data were conflicted when we measured $\mathrm{Ca}^{2+}, \mathrm{Mg}^{2+}$, and Pi urinary excretion and serum levels. We observed that TBTtreated rats had both increased $\mathrm{Ca}^{2+}$ urinary output as well as increased $\mathrm{Ca}^{2+} /$ creatinine ratio (Table 1) suggesting opposite effects. Similar effects were observed for $\mathrm{Mg}^{2+}$ and Pi. These controversial data were even stranger because the only serum mineral ionic parameter that significantly changed in serum was Pi $(11.8 \pm 0.8$ for TBT-treated vs. $7.7 \pm 0.5$ for MOCK treated, $\mathrm{p}=0.038$ ). We did not measure PTH as long as ionized $\mathrm{Ca}^{2+}$ was not altered.

We observed that the animals treated with TBT lose minerals in the urine, and these data corroborate our results of loss of bone mineral mass observed by DXA and by qCT (Fig. 1 and Fig. 2). Urinary $\mathrm{Ca}^{2+}$ output increases in TBT-treated animals $(219.5 \pm 56.2 \mathrm{mg} / 24 \mathrm{~h}$ for TBT-treated vs. $68.7 \pm 36.4 \mathrm{mg} / 24 \mathrm{~h}$; 3-fold increased, $\mathrm{p}=0.012$ ) and excretion fraction $(0.5 \pm 0.1$ for TBT-treated $v s .0 .2 \pm 0.1 ; 2.5$-fold increased, $\mathrm{p}=0.046)$ as well as $\mathrm{Mg}^{2+}$ urinary output $(541.1 \pm 78.5 \mathrm{mg} / 24 \mathrm{~h}$ for TBT-treated vs. $1.0 \pm 0.3 \mathrm{mg} / 24 \mathrm{~h}$; 541 -fold increased, $\mathrm{p}$ $<0.001$ ). Obviously, urinary Pi is elevated as shown by measurements of this output ( 476.3 $\pm 83.5 \mathrm{mg} / 24 \mathrm{~h}$ for TBT-treated vs. $233.2 \pm 56.1 \mathrm{mg} / 24 \mathrm{~h}$; 2 -fold increased, $\mathrm{p}=0.031$ ). While the excretion fraction remains unchanged, statically speaking $\mathrm{Sn}$ is also excreted in higher concentrations in urine as also expected (Table 1).

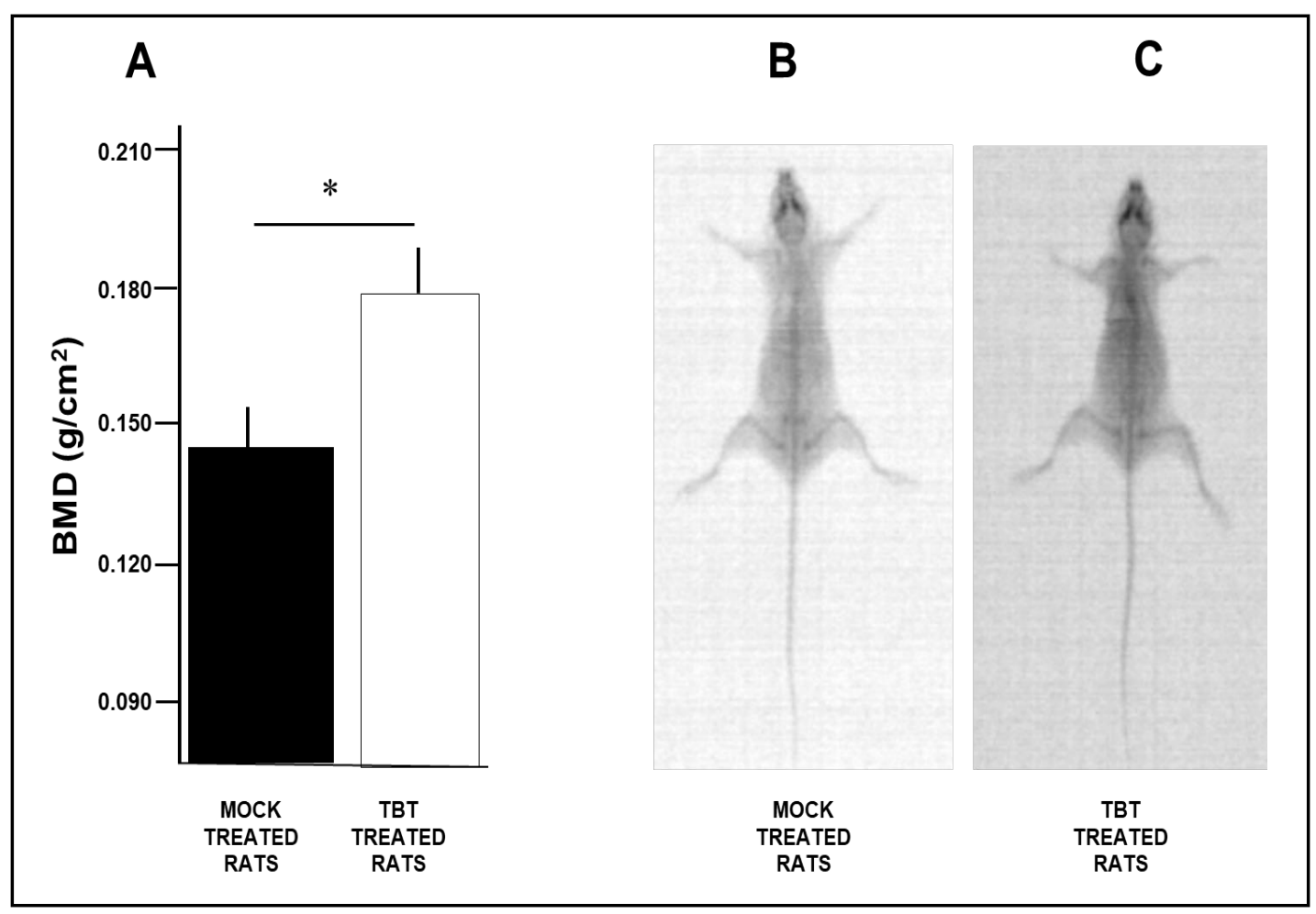

Fig. 1. Dual-Emission X-ray Absorptiometry (DXA) of female rats treated with TBT ( $n=5$, and MOCK Treatedcontrols-rats, treated with only the vehicle of TBT, n=4). A) Data from Bone Mineral Density (BMD) from animal's whole skeletons expressed in average \pm standard error. Graphic shows that TBT-treated animals have an increased in BMD $\left(0.147 \pm 0.010 \mathrm{~g} / \mathrm{cm}^{2}\right)$ when compared to MOCK Treated rats $(0.178 \pm 0.011$ $\mathrm{g} / \mathrm{cm}^{2}, \mathrm{n}=4, \mathrm{p}<0.05$ ). B and C) Representative images of X-Rays from both MOCK Treated rats (B) and TBT-treated animals (C) exhibiting the increased in BMD observed in the former experimental group. Data was analyzed by Student's T test Bonferroni's post hoc correction, considered statistically significant when $\mathrm{p}<0.05$. 


\section{Cellular Physiology Cell Physiol Biochem 2019;52:1166-1177 \begin{tabular}{ll|l} 
and Biochemistry & $\begin{array}{l}\text { DOl: 10.33594/000000079 } \\
\text { Published online: } 17 \text { April 2019 }\end{array}$ & $\begin{array}{l}\text { O 2019 The Author(s). Published by } \\
\text { Cell Physiol Biochem Press GmbH\&Co. KG }\end{array}$ \\
\cline { 2 - 3 } &
\end{tabular} \\ Rangel Resgala et al.: TBT on Rat Bone and Mineral Metabolism}

Table 1. Serum parameters of bone formation biomarkers (serum concentrations of osteocalcin and alkaline phosphatase, evidences of osteoblastic function) and a urinary Deoxypyridinolines/creatinine excretion fraction, (biomarker for collagen degradation and, therefore, osteclastic activation). I addition, Table 1 shows other mineral metabolism elements measurements, particularly, concentrations of plasma and urinary of calcium $\left(\mathrm{Ca}^{2+}\right)$, magnesium $\left(\mathrm{Mg}^{2+}\right)$, urea, and phosphurus (Pi). Renal function was also showed in this table coorbrating previous data from our group [8] such as albuminuria, microalbunuira, and creatinine clearance (calculated by the formula: Ccrea=mass of urinary of creatinine excreted during $24 \mathrm{~h} /$ plasma creatinine, expressed in $\mathrm{dL} / \mathrm{h}$ ) demonstrating that renal failure is taking place in TBT animals as described before by our group $[8,10] .{ }^{*}$ Statically significant, $\mathrm{p}<0.05$

\begin{tabular}{lcc}
\hline Parameters & Control Group (n= 4) & TB Treated Group (n=5) \\
\hline Alkaline Phosphatase (IU/dL) & $127.3 \pm 20.8$ & $137.3 \pm 14.3$ \\
Serum Osteocalcin (pg/dL) & $12.1 \pm 0.2$ & $10.9 \pm 0.9$ \\
Urinary DPD/creatinine & $0.2 \pm 0.1$ & $0.7 \pm 0.2^{*}$ \\
Plasma Total Ca ${ }^{2+}(\mathrm{mg} / \mathrm{dL})$ & $10.3 \pm 1.4$ & $8.5 \pm 2.8$ \\
Plasma Ionized Ca ${ }^{2+}(\mathrm{mg} / \mathrm{dL})$ & $5.2 \pm 0.6$ & $5.7 \pm 0.6$ \\
Plasma Total Mg+ (mg/dL) & $2.2 \pm 0.9$ & $3.3 \pm 0.9$ \\
Plasma Total Pi (mg/dL) & $11.0 \pm 0.8$ & $7.7 \pm 0.5^{*}$ \\
Plasma Creatinine (mg/dL) & $0.5 \pm 0.1$ & $0.6 \pm 0.1$ \\
Plasma Total Sn (ppm) & $0.6 \pm 0.1$ & $324.5 \pm 28.9^{*}$ \\
Urinary Ca ${ }^{2+} / \mathrm{creatinine}$ & $0.2 \pm 0.1$ & $0.5 \pm 0.1^{*}$ \\
Urinary Mg2+/creatinine & $0.6 \pm 0.1$ & $1.4 \pm 0.2^{*}$ \\
Urinary Pi/creatinine & $1.3 \pm 0.3$ & $1.6 \pm 0.2$ \\
Urinary Ca ${ }^{2+}$ Output (mg/24h) & $68.7 \pm 36.4$ & $219.5 \pm 56.2^{*}$ \\
Urinary Mg2+ Output (mg/24h) & $1.0 \pm 0.3$ & $541.2 \pm 78.5^{*}$ \\
Urinary Pi Output (mg/24h) & $233.2 \pm 56.1$ & $476.3 \pm 83.5^{*}$ \\
Urinary Sn Output (ppm/24h) & $0.6 \pm 0.1$ & $123.6 \pm 34.3^{*}$ \\
Creatinine Clearance (mL/24h) & $0.86 \pm 0.10$ & $0.10 \pm 0.01^{*}$ \\
Urinary Output (mL/24h) & $11.7 \pm 2.2$ & $25.7 \pm 3.2^{*}$ \\
Microproteinuria (mg/24h) & $5.6 \pm 2.9$ & $13.9 \pm 2.8^{*}$ \\
Albuminuria (mg/24h) & $148.2 \pm 42.3$ & $252.3 \pm 22.5^{*}$ \\
Uremia (g/24h) & $16.8 \pm 4.2$ & $43.9 \pm 5.2^{*}$ \\
\hline
\end{tabular}

To try reconcile the biochemical and DXA data we determined the bone mineralization and soft tissue using microCT scan. Fig. 2 revealed that TBT-treated animals (Fig. 2 D-CF Panels) exhibited mores soft tissue (organic bone matrix, light gray images in their vertebrae) than controls (Fig. 2 A-C Panels). These images indicated that there is much less mineralized bone in TBT-treated rats although the remaining bone is denser than that obtained from MOCK-treated bone. We used biochemical data to reconcile the DXA data to microCT. We then decided to measure $\mathrm{Sn}$ in dried vertebrae from both groups. Both decalcified and nondemineralized vertebras of TBT-treated rats exhibited 10-fold higher Sn when compared to controls $(34 \pm 5 \mathrm{ppm} / \mathrm{g}$ of tissue/g of animal for TBT-treated animals $v s 2.3 \pm 5 \mathrm{ppm} / \mathrm{g}$ of tissue/g of animal for MOCK animals).

In this paper, we have observed gross anatomy via SEM (2-mm scale) in TBT-treated animals; they have a deterioration of cartilaginous tissue outside the bone vertebrae $(n=3$ vertebrae, 3 different animals) when compared to control group - Fig. 3B) and MOCK rats (Fig. 3A). Micro-scale analysis of external compact bone from TBT-treated rats (Fig. 3C) reveled that the collagen fibers of TBT-treated rats had a decreased diameter than MOCK controls (Fig. 3C and 3D). Moreover, the collagen fibers within the compact bones seemed to be less organized as well. Lower magnification of the inner bone matrix showed a tremendous deleterious effect in bone matrix that corroborated the findings of high osteoclastic activity seen by higher urinary DPD/creatinine excretion. 


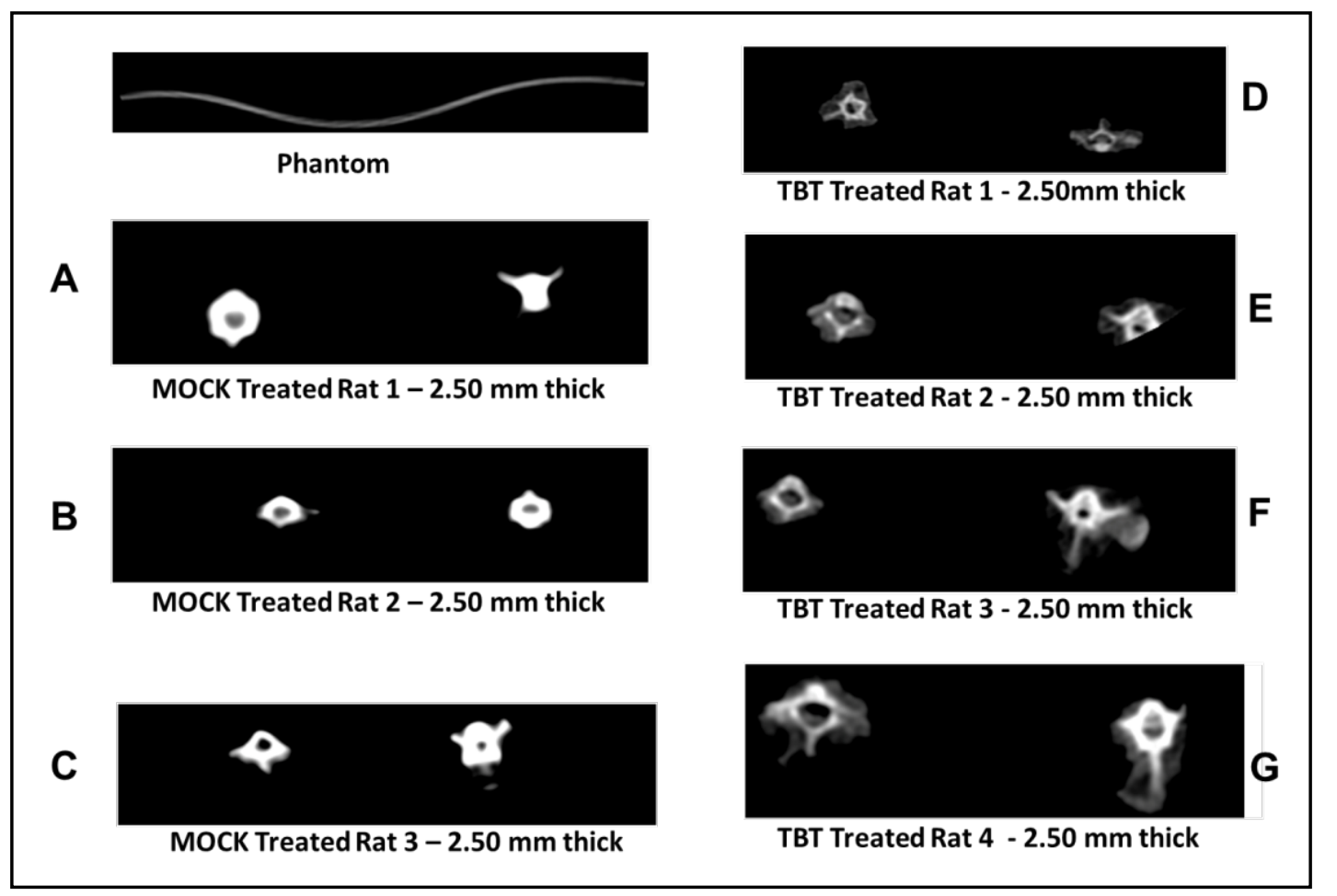

Fig. 2. Micro Computer Tomography Scanning (microCT scan) from vertebral bone of both TBT-treated and MOCK Treated rats. To make sure that both mineral and/or organic matrix were being affected by TBT we analyzed vertebrae from TBT, we evaluated the tri-dimensional cuts from vertebrae (one of the major sites of bone breaking in osteoporosis). A-C show four different TBT-treated MOCK treated at cut-offs of 2.5 mm thick transversal cuts were one can observed abundance of mineralized tissue (higher white signal parameter used appropriate Phantom blocks of calcium carbonate rich seen below.). However, from D-G it is visualized less abundance of mineralized bone whereas sites of soft (less mineralized organic matrix) is still detected in TBT-treated animals $(n=4)$. Quantification of these intensities in proper software indicated that with no doubt that TBT showed, at least in this part of the skeleton less mineralized tissue. Studies with other bones are still in progress.

\section{Discussion}

In this paper, we reported that even low doses of TBT (100 ng/kg/day) for 15 days [7-10] led to changes in bone and mineral metabolism. Bone metabolism is an important resource to maintain extracellular $\mathrm{Ca}^{2+}, \mathrm{Pi}$, and $\mathrm{Mg}^{2+}$ homeostasis in mammals [23-25]. Extensive work has shown that this so-called "mineral metabolism" is regulated mostly by parathyroid hormone (PTH) [26, 27] and the active metabolites of calciferol such as $1 \alpha, 25(\mathrm{OH})_{2}$ vitamin $\mathrm{D}_{3}[24,25]$. However, other hormones play important roles in bone metabolism as well estrogen (E2), thyroid hormone, and glucocorticoids [22, 25 27, 28]. Recently, several xenobiotics have been associated with dysfunctions of endocrine function; hence these are called endocrine disrupting compounds (EDCs) and include TBT.

We have shown that TBT exhibits many deleterious effects in cardiovascular, reproductive, and hypothalamic-pituitary-dependent glands [7-14]. In females, the toxic effects of TBT may be associated with estrogen receptor alpha (ER $\alpha$ ) expression [8-10]. $E R \alpha$ is the major isoform expressed in bone cells especially osteoblasts [29, 30]. Estrogen inhibits the activation of bone remodeling most likely via the osteoclasts. The direct effects of estrogen in bone include the induction of osteoclast apoptosis and the inhibition of osteoclasts formation. In addition to these direct effects on osteoclasts, estrogen also appears to regulate the inhibition osteoblast apoptosis and increase osteoblast lifespan 


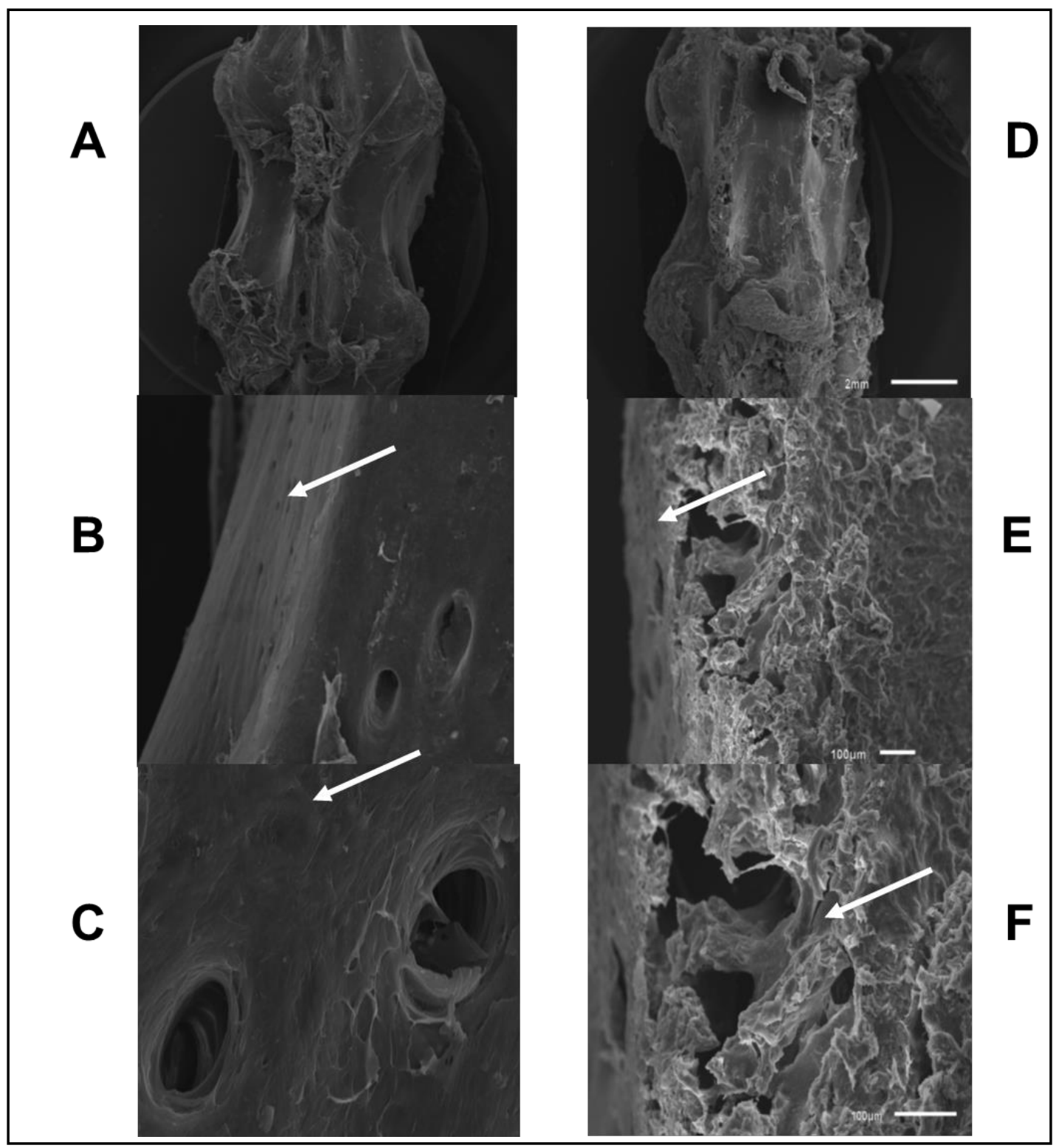

Fig. 3. Evaluation of the vertebral bone ultrastructure through Scanning Electron Microscopy (SEM). SEM was used to analyzed whether there were a change into bone vertebrae bone ultrastructure trying to conciliate the data we obtained so far (all bones use from each, 3 and fourth verterbral bone, animal were cutted three consecutive times and several pictures were taken form than. We consider $n=3$ the number of animals not the number of images taken). From $\mathrm{A}$ to $\mathrm{C}$ we observed representative figures taken from MOCK Treated rat $(\mathrm{n}=3)$ on of $2 \mathrm{~mm}(\mathrm{~A}), 100 \mu \mathrm{m}$, and10 $\mu \mathrm{m}$, respectively. From $\mathrm{D}$ to $\mathrm{F}$ it is observed images taken from vertebrae of TBT-treated animals (also $n=3$ ) at same order of magnificence described previously. Note deterioration of bone matrix and decreased compact bones in TBT-treated animals when compared to controls (arrows) is revealed at level of $\mathrm{mm}$. When examined at $\mu \mathrm{m}$ scale inner bone (spongy bone) shows complete deterioration. Another thing to be pointed out is that external layer (compact bone) is clearly diminished, strongly suggesting that bone in affected deeply by TBT.

[31]. Thus, the TBT-induced estrogen deficiency seems to directly affect the maintenance of bone integrity. Low estrogen production in women after menopause is a major cause of osteoporosis [32, 33]. 


\section{Cellular Physiology Cell Physiol Biochem 2019;52:1166-1177 \\ \begin{tabular}{ll|l} 
and Biochemistry & $\begin{array}{l}\text { DOl: 10.33594/000000079 } \\
\text { Published online: } 17 \text { April 2019 }\end{array}$ & $\begin{array}{l}\text { O 2019 The Author(s). Published by } \\
\text { Cell Physiol Biochem Press GmbH\&Co. KG }\end{array}$ \\
\cline { 2 - 3 } &
\end{tabular} \\ Rangel Resgala et al.: TBT on Rat Bone and Mineral Metabolism}

Baker and co-workers [16] showed that TBT impairs the differentiation of mesenchymal cells in osteoblasts (in vitro model), but nothing has been found on the effects of TBT in bone to date. This was our motivation to investigate the role of TBT in bone and mineral metabolism in a model well-established by our group. However, we know that TBT in this condition severely damages both liver and kidneys $[8,10]$, which are sites of synthesis of the active metabolite of vitamin $\mathrm{D}, 1 \alpha$, and $\left(\mathrm{OH}_{2}\right)$ vitamin $\mathrm{D} 3[22,25]$. Thus, our results indicate that organotin stress severely alters functional metabolism. However, tin accumulates in many organs and this metal could dislocate divalent cations from bones. There was a tremendous increase in serum Sn of TBT-treated animals as expected (Table 1). This led a 2 -fold increase of this heavy metal in the bones of treated animals versus controls (data not shown). Although the levels of Sn found in bones of TBT-treated animals were far lower than those seen in Baker and co-workers [16], the effect may be plausible because the amount of bone tissue (1 vertebrae more or less $1 \mathrm{mg}$ ) ought to be multiplied by the total skeleton weight to estimate total tin retained in bone from TBT-treated animals. Nonetheless, the hypothesis of deregulation of PTH-vitamin D axis may not be ruled out at this moment and more details on needed on the cause of low bone mineral density (BMD).

We have previously shown that TBT damages both kidneys and adrenals [10, 13], and thus we measured some renal impact on bone mineral. TBT-treated animals had higher urinary output, albuminuria, microproteinuria, and uremia-all clear symptoms of renal dysfunction (Table 1). These parameters have already been reported [8-10]. These data suggest two things according to a previous paper published from our group: 1) First, the hyperphosphatemia is likely due to the higher filtration rate of Pi because there was a simultaneous decrease in plasma $\mathrm{Pi}$ and increased urinary mass of $\mathrm{Pi} ; 2$ ) The effect of PTH must be minimized since it is the principal hormone responsible for proximal tubule $\mathrm{Pi}$ secretion. This can be seen whether the Pi/creatinine ratios were different among TBTtreated and MOCK-treated groups. Taken together, these data suggest that the deleterious effects of TBT in BMD might be associated with the PTH - Vitamin D axis.

Our group has shown that the mineralized content of the bone matrix can be changed in females via E2; therefore, disruptors of E2 effects must have profound actions on bone tissue [6-14]. Taken together, it is plausible that, at least $\mathrm{Sn}^{2+}$, might be competing at some level with $\mathrm{Ca}^{2+}$ and $/ \mathrm{Mg}^{2+}$ in mineralization of organic bone matrix. If this were true, could explain why osteoblastic activity remains normal whereas DPD/creatinine urinary excretion is elevated in TBT animals increased looking like a higher bone resorption. Our group has studied the bone and mineral metabolism previously $[21,26,34,35]$. To check the status the bone matrix we used SEM to examine the bone ultrastructure. Recently, we studied the role of hormones and other molecules in bone ultrastructure in murine models using both microCT and DXA along with classical histochemical, molecular, and biochemical methods [26, 34, 35]. Both SEM and TEM can explain bone matrix changes during osteopenia/osteoporotic that cannot be seen in vivo. The microCT can study pharmacological and situations in response to genetic alterations [unpublished data].

\section{Conclusion}

Therefore, our data lead to three possible explanations for the deleterious TBT effects in bone. First, the PTH-vitamin D axis might be disrupted at some point because of the liver and kidney dysfunctions already reported by our group $[8,10]$. Second, Sn might be exchanged by $\mathrm{Ca}^{2+}$ and $/ \mathrm{Mg}^{2+}$ within bone impairing bone formation. Baker and Co-workers [16] demonstrated deregulation of the differentiation of osteoprogenitor mesenchymal cells in osteoblasts leading to a balance in bone resorption versus formation. Third, 27-hidroxicholesterol, a metabolite of cholecalciferol as proposed by He \& Nelson [32], might have adjuvant effects with TBT in the protective E2 in bone leading to osteoblast 


\section{Cellular Physiology Cell Physiol Biochem 2019;52:1166-1177

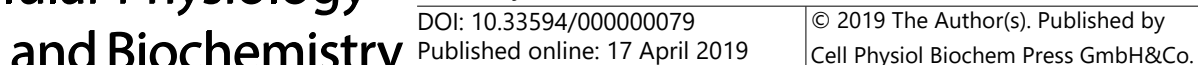 \\ Rangel Resgala et al.: TBT on Rat Bone and Mineral Metabolism}

inactivation and apoptosis. This leads to less bone formation. Nonetheless, we are exploring all three possibilities. Regardless of the hypothesis to be confirmed, it is clear that the stress induced by TBT severely alters the maintenance of the bone mineral mass. It induces early osteoporosis and is an important environmental factor related to this disease.

\section{Acknowledgements}

The authors thank FACITEC [no. 017/2006 and no. 036/2006], FAPES [no. 172.1/2005; no.72630477/2014 and no. 179/2017], DECIT-SUS [no. 31614990/2005], CNPq [no. 480807/2006; no. 304724/2017-3 and no. 12/2017] and CNPq/FAPES-PRONEX (no. $572 / 2018$ ) for financial support. Funding to LCFL and NFGR was also provided by FAPES (no.1423568-2016 and 1014-2015, respectively). The authors would also gratefully acknowledge the Centro de Diagnóstico e Pesquisa da Osteoporose do Espírito SantoCEDOES (Vitória/ES, Brazil) and Instituto Tommasi de Pesquisa e Desenvolvimento (Vila Velha, Brazil). One of the authors (O. M. Santamaria Niño) thanks Universidad de los Llanos for providing the opportunity for this work and his stay in the Federal University of Espirito Santo. Also thank Federal University of Espírito Santo for scholarships and local expenses and core supports.

\section{Disclosure Statement}

The authors declare that they have no conflicts of interest.

\section{References}

1 Alzieu C, Sanjuan J, Deltreil JP, Borel M: Tin contamination in Arcachon bay: effects on oyster shell anomalies. Mar Pollut Bull 1986;17:494-498.

2 Aono A, Takeuchi I: Effects of tributyltin at concentrations below ambient levels in seawater on Caprella danilevskii (Crustacea:Amphipoda:Caprellidae). Mar Pollut Bull 2008;57:515-523.

3 Morezesk M, Bonomo MM, Rocha LD, Duarte ID, Zanezil ERL, Jesus HC, Fernandes MN, Matsumoto ST: Landfill Leachate Sludge Use as Soil Additive Prior and After Electrocoagulation Treatment: A Cytological Assessment Using CHO-K1 Cells. Chemosphere 2016;157:66-71.

4 Delgado Filho, VC, Mancini CN, Silva IV, Pedrosa DF, Destefani AC, Samoto YM, Takya CM, Graceli JB. Endocrine Disruption Induced by Triorganotin (iv) Compounds: Impacts in the Reproductive and Genetic Function. Med Genet Genomics 2010;2:29-37.

5 Delgado Filho VS, Lopes PFI, Podratz PL, Graceli JB: Triorganotin as a Compound with Potential Reproductive Toxicity in Mammals. Braz J Med Biol Res 2011;44:958-965.

6 Podatz PL, Merlo E, Sena GS, Morzesk M, Bonomo MM, Matsumoto ST, da Costa MB, Zamprogno GC, Brandão PA, Carneiro MT, Miguel Ede C, Miranda-Alves L, Silva IV, Graceli JB: Accumulation of Organotins in Seafood Leads to Reproductive Tract Abnormalities in Female Rats. Reprod Toxicol 2015;57:29-42.

7 Merlo E, Podratz PL, Sena GC, de Araújo JF, Lima LC, Alves IS, Gama-de-Souza LN, Pelição R, Rodrigues LC, Brandão PA, Carneiro MT, Pires RG, Martins-Silva C, Alarcon TA, Miranda-Alves L, Silva IV, Graceli JB: The Environmental Pollutant Tributyltin Chloride Disrupts the Hypothalamic-Pituitary-Adrenal Axis at Different Levels in Female Rats. Endocrinol 2016;157:2978-2995.

8 Coutinho JVS, Freitas-Lima LC, Freitas FF, Freitas FP, Podratz PL, Magnago, RP, Porto ML, Meyrelles SS, Vasquez EC, Brandão PA, Carneiro MT, Paiva-Melo FD, Miranda-Alves L, Silva IV, Gava AL, Graceli JB: Tributyltin Chloride Induces Renal Dysfunction by Inflammation and Oxidative Stress in Female Rats. Toxicol Lett 2016;260:52-69. 


\section{Cellular Physiology Cell Physiol Biochem 2019;52:1166-1177 \begin{tabular}{l|l|l} 
and Biol: 10.33594/000000079 & (c) 2019 The Author(s). Published by
\end{tabular} and BIOChemistry Published online: 17 April $2019 \quad$ Cell Physiol Biochem Press GmbH\&Co. KG \\ Rangel Resgala et al.: TBT on Rat Bone and Mineral Metabolism}

- 9 Ximenes CF, Rodrigues SML, Podratz PL, Merlo E, de Araújo JFP, Rodrigues LCM, Coitinho JB, Vassallo DV, Graceli JB, Stefanon I: Tributyltin Chloride Disrupts Aortic Vascular Reactivity and Increases Reactive Oxygen Species Production in Female Rats. Environ Sci Pollut Res Int 2017;24:24509-24520.

- 10 Bertuloso BD, Podratz PL, Merlo E, De Araújo JFP, Lima LCF, Miguel EC, de Souza LN, Gava AL, de Oliveira M, Miranda-Alves L, Carneiro MT, Nogueira CR, Graceli JB: Tributyltin Chloride Leads to Adiposity and Impairs Metabolic Functions in the Rat Liver and Pancreas. Toxicol Lett 2015;235:45-59.

- 11 Ribeiro Junior RF, Marques VB, Nunes DO, Ronconi KS, de Araújo JF; Rodriguez PL, Padilha AS, Vassallo DV, Graceli JB, Stefanon I: Tributyltin Chloride Increases Phenylephrine-induced Contraction and Vascular Stiffness in Mesenteric Resistance Arteries from Female Rats. Toxicol Appl Pharmacol 2016;15:26-36.

- 12 Rodrigues SM, Ximenes CF, de Batista PR, Simões FV, Coser PH, Sena GC, Podratz PL, de Souza LN, Vassallo DV, Graceli JB, Stefanon I: Tributyltin Contributes in Reducing the Vascular Reactivity to Phenylephrine in Isolated Aortic Rings from Female Rats. Toxicol Lett 2014;225:378-385.

13 dos Santos RL, Podratz PL, Sena GC, Filho VS, Lopes PF, Gonçalves WL, Alves LM, Samoto VY, Takiya CM, de Castro Miguel E, Moysés MR, Graceli JB: Tributyltin Impairs the Coronary Vasodilation Induced by 17ß-Estradiol in Isolated Rat Heart. J Toxicol Environ Health 2012;75:948-959.

- 14 Sena GC, Freitas-Lima LC, Merlo E, Podratz PL, de Araújo JF, Brandão PA Carneiro MT, Zicker MC, Ferreira AV, Takiya CM, de Lemos Barbosa CM, Morales MM, Santos-Silva AP, Miranda-Alves L, Silva IV, Graceli JB: Environmental Obesogen Tributyltin Chloride Leads to Abnormal Hypothalamic-pituitary-gonadal Axis Function by Disruption in Kisspeptin/leptin Signaling in Female Rats. Toxicol Appl Pharmacol 2017;319:22-38.

- 15 Santos-Silva AP, Andrade MN, Perereira-Rodrigues P, Paiva-Melo FD, Soares P, Graceli JB, Miranda Alves L: Frontiers in Endocrine Disruption: Impacts of Organotin on the Hypothalamus-pituitary-thyroid axis. Mol Cell Endocrinol 2018;460:246-257.

- 16 Baker AH, Watt J, Huang CK, Gerstenfeld LC, Schlezinger JJ: Tributyltin engages multiple nuclear receptor pathways and suppresses osteogenesis in bone marrow multipotent stromal cells. Chem Res Toxicol 2015;28:1156-1166.

- 17 Baker AH, Wu TH, Bolt AM, Gerstenfeld LC, Mann KK, Schlezinger JJ: From the Cover: Tributyltin Alters the Bone Marrow Microenvironment and Suppresses B Cell Development. Toxicol Sci 2017;158:63-75.

18 Zhou J, Zhu XS, Cai ZH. Tributyltin toxicity in abalone (Haliotis diversicolor supertexta) assessed by antioxidant enzyme activity, metabolic response, and histopathology. J Hazard Mater 2010;183:428-433.

19 Grün F, Watanabe H, Zamanian Z, Maeda L, Arima K, Cubacha R, Gardiner DM, Kanno J, Iguchi T, Blumberg B: Endocrine-disrupting organotin compounds are potent inducers of adipogenesis in vertebrates. Mol Endocrinol 2006;20:2141-2155.

- 20 Penza M, Jeremic M, Marrazzo E, Maggi A, Ciana P, Rando G, Grigolato PG, Di Lorenzo D: The environmental chemical tributyltin chloride (TBT) shows both estrogenic and adipogenic activities in mice which might depend on the exposure dose. Toxicol Appl Pharmacol 2011;255:65-75.

- 21 Silva IV, Cebotaru V, Wang H, Wang XT, Wang SS, Guo G, Devuyst O, Thakker RV, Guggino WB, Guggino SE: The ClC-5 knockout mouse model of Dent's disease has renal hypercalciuria and increased bone turnover. J Bone Miner Res 2003;18:615-623.

- 22 Pike JW, Christakos S: Biology and Mechanisms of Action of the Vitamin D Hormone. Endocrinol Metab Clin North Am 2017;46:815-843.

- 23 Watt J, Baker AH, Meeks B, Pajevic PD, Morgan EF, Gerstenfeld LC, Schlezinger JJ. Tributyltin induces distinct effects on cortical and trabecular bone in female C57Bl/6J mice. J Cell Physiol 2018;233:70077021.

24 Sturgeon CM, Sprague S, Almond A, Cavalier E, Fraser WD, Algeciras-Schimnich A, Singh R, Souberbielle JC, Vesper HW: Perspective and priorities for improvement of parathyroid hormone (PTH) measurement A view from the IFCC Working Group for PTH. Clin Chim Acta 2017;467:42-47.

- 25 Anderson PH: Vitamin D Activity and Metabolism in Bone. Curr Osteoporos Rep 2017;15:443-449.

- 26 Souza LS, Rochette NFG, Pedrosa DF, Magnago RLM, Freire Filho TB, Vieira FLH, Fin IDCF, Eis SR, Graceli JB, Rangel LBA, Silva IV: Role of APOE Gene in Bone Mineral Density and Incidence of Bone Fractures in Brazilian Postmenopausal Women. J Clin Densitom 2018;21:227-235.

- 27 Barstow C: Electrolytes: Calcium Disorders. FP Essent 2017;459:29-34.

- 28 Khalil R, Kim NR, Jardi F, Vanderschueren D, Claessens F, Decallonne B: Sex steroids and the kidney: role in renal calcium and phosphate handling. Mol Cell Endocrinol 2018;465:61-72. 
29 Pavone V, Testa G, Giardina SMC, Vescio A, Restivo DA, Sessa G: Pharmacological Therapy of Osteoporosis: A Systematic Current Review of Literature. Front Pharmacol 2017;8:803.

- 30 Rooney AM, van der Meulen MCH: Mouse models to evaluate the role of estrogen receptor $\alpha$ in skeletal maintenance and adaptation. Ann N Y Acad Sci 2017;1410:85-92.

- 31 Kousteni S, Bellido T, Plotkin LI, O’Brien CA, Bodenner DL, Han L, Han K, DiGregorio GB, Katzenellenbogen JA, Katzenellenbogen BS, Roberson PK, Weinstein RS, Jilka RL, Manolagas SC: Nongenotropic, sexnonspecific signaling through the estrogen or androgen receptors: dissociation from transcriptional activity. Cell 2001;104:719-730.

- 32 He S, Nelson ER: 27-Hydroxycholesterol, an endogenous selective estrogen receptor modulator. Maturitas 2017;104:29-35.

33 Eshraghian A: Bone metabolism in non-alcoholic fatty liver disease: vitamin D status and bone mineral density. Minerva Endocrinol 2017;42:164-172.

34 De Siqueira D, Miguel EC, Eis SR, Rangel LC, Cunha M, Meyrelles SS, Vasquez EC, Silva IV: Ultra Structural Analysis From Bone APOE Knock Out Mice. Maturitas 2012;71:S22.

35 Silva IV, Blaisdell CJ, Guggino SE, Guggino WB: PTH regulates expression of ClC-5 chloride channel in the kidney. Am J Physiol Renal Physiol 2000;278:F238-F245. 